\title{
The Effects of Cleaning on the Kinetics of in vitro Metal Release from Dental Casting Alloys
}

\author{
J.C. WATAHA, R.G. CRAIG, and C.T. HANKS
}

The University of Michigan School of Dentistry, 1011 N. University Avenue, Ann Arbor, Michigan 48109-1078

The kinetics of the release of elements from six dental casting alloys into cell-culture medium was assessed by means of atomic absorption spectroscopy. Alloys were evaluated in the polished and polished-cleaned conditions so that the effects of cleaning could be determined. Auger scanning microscopy was used for analysis of the surfaces of selected alloys before and after exposure to the cell-culture medium. Release patterns for each element were characterized by the shape of the dissolution $v s$. time curve, concentration of the element at $12 \mathrm{~h}$ as a percentage of the 72-hour concentration, and the relative slope of the curve from 48 to $72 \mathrm{~h}$. Three patterns of release were observed for elements in these alloys. Type I patterns had logarithmic shapes with relatively large 12 -hour concentrations and low 4872-hour slopes. Type II patterns had logarithmic shapes but with moderate 12-hour concentrations and 48-72-hour slopes. Type III patterns were polynomial in shape, had relatively low 12-hour concentrations, and had large 48-72-hour slopes. Cleaning did not change the pattern of release but did generally significantly decrease the quantities of elements released $(p=0.05)$. The type of dissolution vs. time curve appeared to be dependent upon the element and the composition of the alloy. When cleaning reduced dissolution, surface analyses showed that the cleaning process increased the abundance of elements such as $\mathrm{Au}$ and $\mathrm{Pd}$ and reduced the abundance of $\mathrm{Ag}$ and $\mathrm{Cu}$. Elements which were released from the alloys were more abundant on the surface than in the bulk in both polished and polishedcleaned conditions. Auger analyses of alloy surfaces after exposure to medium showed the presence of organic films up to $50 \mathrm{~nm}$ thick. This study demonstrated the importance of consideration of the cleaning method and kinetic release pattern when in vitro tests which assess the cytotoxicities of these alloys are planned.

\section{J Dent Res 71(7):1417-1422, July, 1992}

\section{Introduction.}

The release of elements from dental alloys in vivo may cause local or systemic problems. For example, Hao and Lemons (1989) showed that copper released from $\mathrm{Cu}$-based dental alloys accumulated in canine gingival tissues and caused gingival thickening and inflammation. Greppi et al. (1991) showed that nickel-containing orthodontic wires and brackets could trigger systemic and local allergic responses when inserted into patients who were hypersensitive to nickel. Because of these problems, there have been numerous investigations into the quantities of elements released in vitro from several types of dental casting alloys. For example, Wright et al. (1982) demonstrated that the copper released from $\mathrm{Au}-\mathrm{Cu}-\mathrm{Ag}$ alloys correlated with the in vitro cytotoxicity of these alloys. Covington et al. (1985) reported that beryllium-containing base-metal alloys released significant nickel and beryllium below $\mathrm{pH} 6$. Wataha et al. (1991) showed that element release into cell-

Received for publication October 3, 1991

Accepted for publication January 23, 1992

This investigation was supported by USPHS Grants F32 DE05584 and P50 DE09296 from the National Institute of Dental Research, National Institutes of Health, Bethesda, MD 20892. culture medium from a variety of dental casting alloys was not proportional to the atomic percentage of those elements in the alloys.

There has also been research into the kinetics of the release of elements from dental casting alloys. Bergman and Ginstrup (1975) measured the dissolution rate of $\mathrm{Cd}, \mathrm{Cu}$, and $\mathrm{Zn}$ from dental gold solders by means of anodic polarization. Lappalainen and Yli-Urpo (1987) used anodic polarization for analysis of high-gold casting alloys and dental amalgam and quantified the release of elements over time from these alloys. Brune (1988) quantified the release of elements from stainless-steel, chromium-cobalt alloys, and dental amalgam by means of nuclear corrosion monitoring and ESCA. He found that these alloys selectively released elements which often resulted in passivation of the alloy surfaces. Several researchers have investigated the kinetics of the release of elements from Ni-Cr-Mo alloys by means of atomic absorption spectroscopy (Muller et al., 1990; Geis-Gerstorfer et al., 1991). There have been fewer attempts to investigate the effects of the alloy-cleaning process on the release of elements, yet some researchers have shown that the cleaning process is important in influencing the biological response to an alloy (Baier et al., 1984).

The aims of this study were to (1) determine the in vitro kinetic patterns of release of elements from several types of dental casting alloys which are used commercially, (2) determine the effects of an alloy-cleaning procedure on the release of elements, and (3) correlate the rate of release of elements with Auger surface analyses of the alloys. Knowledge about the kinetic patterns of element release from alloys and about the cleaning effects on this release may give insight into mechanisms by which alloys release elements, provide new strategies for structuring in vitro tests used for evaluation of the biocompatibility of these alloys, and provide information useful for predicting the in vivo performance of these alloys.

\section{Materials and methods.}

Sample composition and preparation.-Six dental casting alloys were used; there were six sample replicates per alloy. These alloys were chosen based on a previous study which showed that they released significant amounts of their elements after exposure to cell-culture medium for $72 \mathrm{~h}$ (Wataha et al., 1991). Atomic percentage compositions and microstructures of these alloys are shown in Table 1 . The samples were discs with diameters of $5.4 \mathrm{~mm}$, with a $1-\mathrm{cm}$ stem attached to one face of the disk.

Polishing and cleaning procedures for the samples have been previously described in detail (Wataha et al., 1991). Briefly, the disk face opposite the stem and the axial portions of the disc were polished with Tripoli and rouge on $2.5-\mathrm{cm}$ rag wheels. In experiments where the samples were cleaned, they were scrubbed with Alconox and Jelenko Polishing Compound Remover (Jelenko, Armonk, NY 10504), treated ultrasonically, then rinsed with double-distilled water, $95 \% \mathrm{v} / \mathrm{v}$ ethanol, and sterile water.

Kinetics of element release. - Each sample was placed into a well of a 24-well cell-culture dish with $0.5 \mathrm{~mL}$ of cell-culture medium. The polished surface area of the samples exposed to cell-culture 
(a)

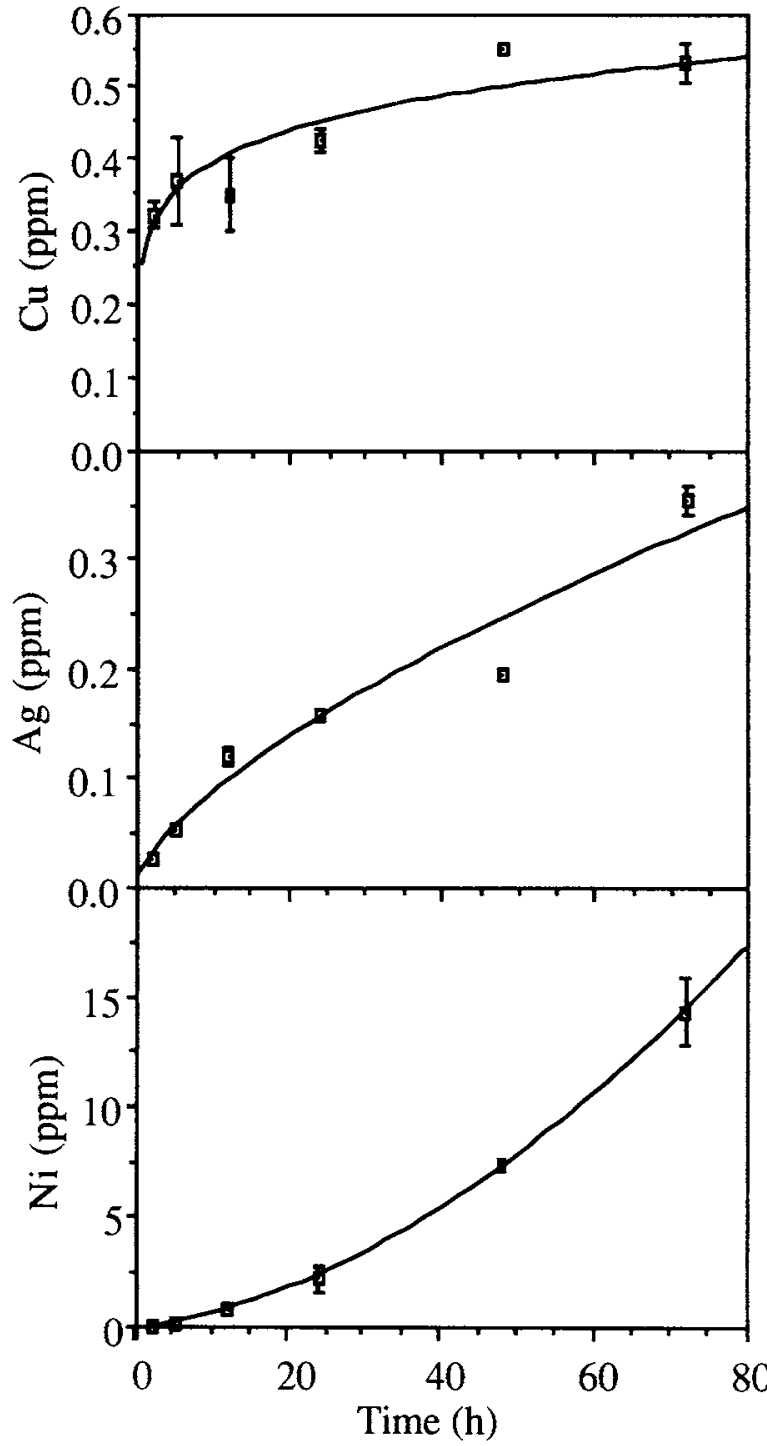

Fig. 1-Examples of concentration us. time curves for elements released from dental alloys. Curves were fitted by the least-squares method. (a) $\mathrm{Cu}$, alloy 1 , an example of a type $I$ curve $\left(r^{2}=0.85\right)$. Cu concentrations increased rapidly in a logarithmic pattern with a low slope between 48 and $72 \mathrm{~h}$. (b) Ag from alloy 4, an example of a type II curve $\left(r^{2}=0.97\right)$. Ag concentrations increased gradually in a logarithmic curve with a moderate slope between 48 and $72 \mathrm{~h}$. (c) $\mathrm{Ni}$, alloy 6 , an example of a type III curve $\left(\mathrm{r}^{2}=0.99\right)$. $\mathrm{Ni}$ concentration increased slowly in a polynomial curve and had a relatively large slope between 48 and $72 \mathrm{~h}$.

medium was $65 \mathrm{~mm}^{2}$. Cell-culture medium consisted of Dulbecco's Modified Eagle's Medium without glutamine (Flow, McLean, VA 22102 ), $3 \% \mathrm{v} / \mathrm{v}$ NuSerum (Collaborative Research, Inc., Bedford, MA 01730), $28 \mathrm{mmol} / \mathrm{L}$ HEPES (N-2-hydroxyethylpiperazine-N'-2ethanesulfonic acid, $\mathrm{pH}=7.2$ ), penicillin ( 125 units $/ \mathrm{mL}$ ), streptomy$\operatorname{cin}(125 \mu \mathrm{g} / \mathrm{mL})$, gentamycin $(10 \mu \mathrm{g} / \mathrm{mL})$, and glutamine $(2 \mathrm{mmol} / \mathrm{L})$. The samples and medium were incubated at $37^{\circ} \mathrm{C}$ in $5 \% \mathrm{CO}_{2}, 95 \%$ air, and $100 \%$ relative humidity. After incubation, the medium around the samples was swirled gently, collected from the wells, and centrifuged for $10 \mathrm{~min}$ at $220 \mathrm{~g}$. The supernate (no solid material was visible) was then analyzed for the elements in the alloys by means of flame atomic absorption (Perkin Elmer 3030B, Norwalk, CT 06859). The wavelengths and detection limits for the atomic absorption analyses are shown in Table 2.

Each experimental replication was used for testing the effects of one incubation time; incubation times of $2,5,12,24,48$, and
$72 \mathrm{~h}$ were tested. The samples were re-polished and re-cleaned before each experiment. Experimental replicates were performed as follows: four replications at $2 \mathrm{~h}$, three at $5 \mathrm{~h}$, two at $12 \mathrm{~h}$, one at $48 \mathrm{~h}$, and five at $72 \mathrm{~h}$. Unexposed cell-culture medium was tested for all elements in each experimental replication, and these concentrations were subtracted from the experimental values when appropriate.

The concentrations of the elements in the medium were plotted against incubation times, and curves were fitted to the points by use of the least-squares method. Equations for the curves which accounted for the most variation in the dependent variable were used. Three characteristics of these curves were evaluated. First, the mathematical shape of the curve was noted. Second, the concentration of an element which was present at $12 \mathrm{~h}$ was expressed as a percentage of the amount released at $72 \mathrm{~h}(12 \mathrm{~h} \%$ conc). Third, the relative slope of the curve from 48 to $72 \mathrm{~h}$ was calculated by dividing the slope during that time by the concentration of the element in the medium at $72 \mathrm{~h}$. The units for the relative slope were concentration/ $\mathrm{h}$ /concentration or simply $\mathrm{h}^{-1}$. These three parameters provided information relevant to the in vitro and in vivo performance of these alloys. Errors for the 12-hour percent concentrations and relative slopes were assessed graphically and were approximately $15 \%$ at $\mathrm{p}=0.05$.

Effect of cleaning on release.-For this series of experiments, the alloys shown in Table 1 were polished but were not cleaned. The alloys were then incubated with cell-culture medium as described above for either 2 or $72 \mathrm{~h}$; there were three experimental replicates for each time period. Concentrations of elements released into the cell-culture medium were compared with those seen with the cleaned samples. The differences between cleaned and uncleaned samples were calculated at 2 and $72 \mathrm{~h}$, and Student's $t$ tests were used for detection of significant differences at $\mathrm{p}=0.05$.

Surface analysis.-Scanning Auger Microscopy was performed by Surface Science Western (London, Ontario) and was used for evaluation of the atomic percentage composition of elements in alloys 1,4 , and 9 at the surface and to a depth of $25 \mathrm{~nm}$. Analyses were done on a PHI 600 microprobe with a $3-\mathrm{kV}$ electron beam and $100 \mathrm{nA}$ of current. Depth profiles were produced by etching the alloy surface with a $3 \mathrm{kV}$ electron beam at $25 \mathrm{~nm} /$ min over an area of 2 by $2 \mathrm{~mm}$, with the etching process interrupted for surface evaluation. The atomic percentage composition of elements was plotted against depth of the etch for three conditions: polished but not cleaned, polished-cleaned, and polished-cleaned and exposed to cell-culture medium for $72 \mathrm{~h}$.

\section{Results.}

Kinetics of element release.-Three types of concentration us. time curves were observed for the elements in these alloys. Type I curves [Fig. 1(a)] were characterized by their logarithmic shape, 12-hour percentage concentrations greater than $50 \%$, and relative 48-72-hour slopes less than $0.005 \mathrm{~h}^{-1}$. Type II curves [Fig. 1(b)] were characterized by a logarithmic shape, 12-hour percentage concentrations between 10 and $50 \%$, and relative 48-72-hour slopes from $0.005-0.015 \mathrm{~h}^{-1}$. Type III curves [Fig. 1(c)] had a second-order polynomial shape with 12-hour percentage concentrations less than $10 \%$ and a relative $48-72-$ hour slope greater than $0.015 \mathrm{~h}^{-1}$. The kinetic characteristics of the release of elements from all of the alloys are listed in Table 3. Alloys for which data on elements are not shown released concentrations of elements too low to permit kinetic analyses. Ag exhibited a type II curve in all alloys which released $\mathrm{Ag}$. $\mathrm{Cu}$ exhibited a type I curve in all alloys except alloy 9 , where it had a type II curve. All three types of curves 


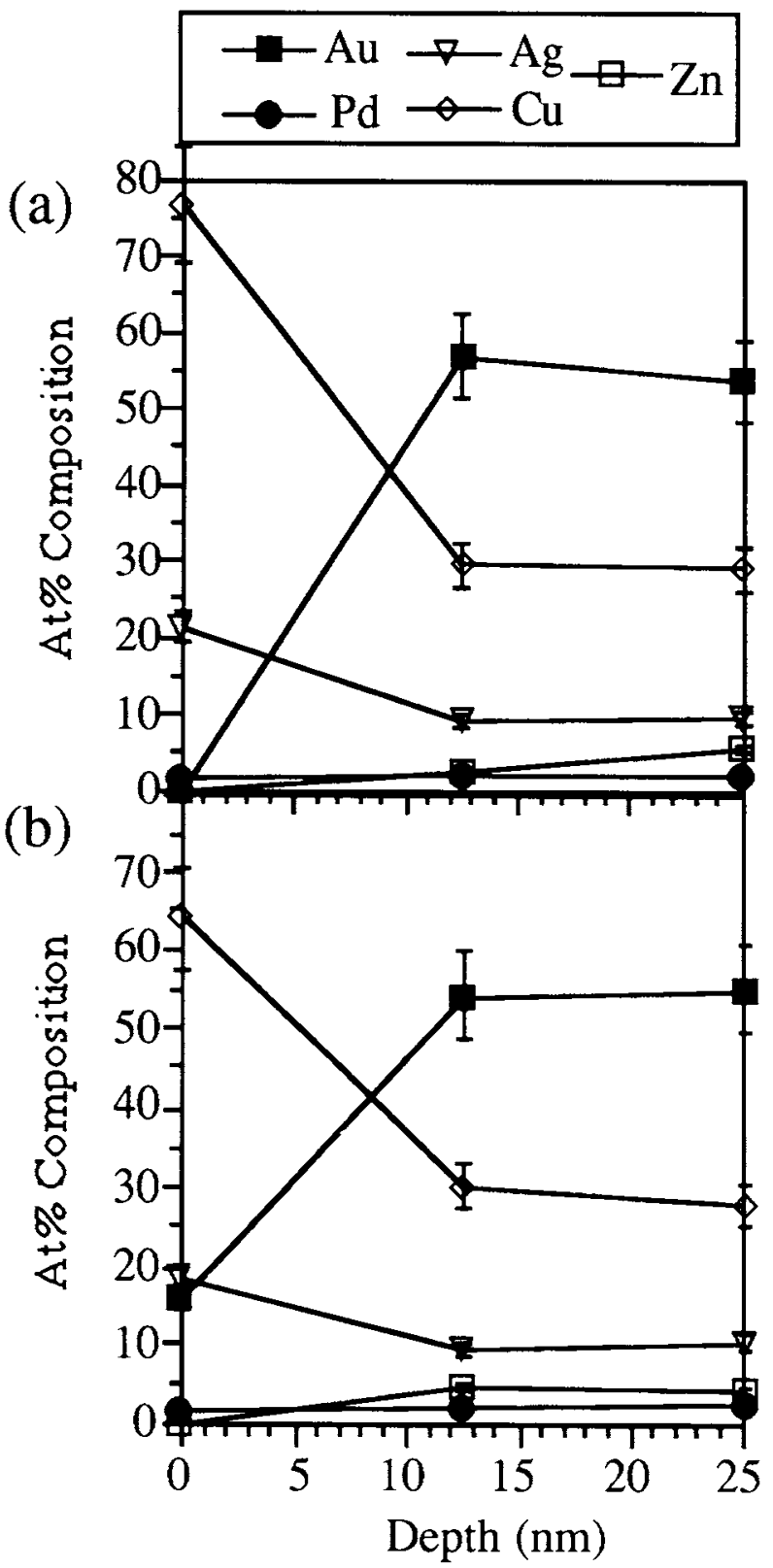

Fig. 2-Auger surface-analysis of alloy 1. (a) In the polished condition, the surface of the alloy was richer in $\mathrm{Ag}$ and $\mathrm{Cu}$ and poorer in $\mathrm{Au}$, $\mathrm{Pd}$, and $\mathrm{Zn}$ than the bulk. The bulk percentages of the elements were present at a depth of $12.5 \mathrm{~nm}$. (b) Cleaning reduced the surface percentages of $\mathrm{Ag}$ and $\mathrm{Cu}$ and increased the percentage of $\mathrm{Au}$. Error bars represent $95 \%$ confidence intervals based upon graphical analyses of the

were observed from elements in the multiple-phase alloys $(6$ and 10), but type III curves were not seen from elements in the single-phase alloys (Tables 1 and 3 ).

Effect of cleaning on release.-Table 4 lists the concentrations of elements released from alloys after 2 and $72 \mathrm{~h}$ in the polished and polished-cleaned conditions. Cleaning reduced dissolution of elements after $72 \mathrm{~h}$ except for alloy 9 , which showed an increase in dissolution. At $2 \mathrm{~h}$, cleaning reduced dissolution of $\mathrm{Cd}, \mathrm{Cu}$, increased dissolution of $\mathrm{Ni}$, and did not affect $\mathrm{Ag}$ and $\mathrm{Ga}$ significantly. Dissolution from both singleand multiple-phase alloys was affected by the cleaning process (Tables 1 and 4).



Fig. 3-Auger surface-analysis of alloy 9. (a) After being polished, the surface of the alloy was richer in $\mathrm{Ag}, \mathrm{Cu}$, and $\mathrm{Zn}$ and poorer in $\mathrm{Au}$ and $\mathrm{Pd}$ than the bulk. (b) Cleaning decreased surface $\mathrm{Cu}$, increased $\mathrm{Ag}$ slightly, and left $\mathrm{Au}$ and $\mathrm{Zn}$ unchanged. The percentages of $\mathrm{Ag}$ and $\mathrm{Cu}$ were near their eutectic composition after the alloy was cleaned. No Au was detected at the surface in the polished or polished-cleaned conditions. Error bars represent $95 \%$ confidence intervals based upon graphical analyses of the Auger spectra.

Surface analysis. - Depth profiles of elements for alloy 1 in the polished and polished-cleaned conditions are shown in Fig. 2 . In the polished condition, the surface of this alloy was relatively rich in $\mathrm{Ag}$ and $\mathrm{Cu}$ compared with $\mathrm{Au}, \mathrm{Pd}$, and $\mathrm{Zn}$. At a depth of $12.5 \mathrm{~nm}$, the atomic percentages of the elements had reached their bulk values [Fig. 2(a) and Table 1]. When the alloy was cleaned, the abundance of Ag decreased by about 3 at. $\%, \mathrm{Cu}$ decreased by 10 at.\%, and Au increased by 13 at.\% [Fig. 2(b)]. The cleaned samples also exhibited bulk compositions at the 12.5 -nm depth.

In the polished condition, surface analysis of alloy 4 indicated that the surface was about 5 at.\% richer in $\mathrm{Ag}$ and $\mathrm{Cu}$ and 10 at.\% 
TABLE 1

COMPOSITIONS AND MICROSTRUCTURES OF ALLOYS

\begin{tabular}{|c|c|c|c|c|c|c|c|}
\hline \multirow[t]{2}{*}{$\overline{\text { Alloy }}$} & \multicolumn{6}{|c|}{ at.\% Composition } & \multirow[t]{2}{*}{ Microstructure } \\
\hline & $\mathrm{Ag}$ & $\overline{\mathrm{Au}}$ & $\mathrm{Cu}$ & $\mathrm{Pd}$ & $\mathrm{Zn}$ & Other & \\
\hline 1 & 11.5 & 49.8 & 31.5 & 2.6 & 3.2 & Pt 1.4 & Single-phase \\
\hline 4 & 62.7 & 1.6 & 10.6 & 22.5 & 0.8 & In 1.8 & Single-phase \\
\hline 5 & 15.2 & 46.6 & 25.6 & - & 3.4 & $\operatorname{Cd} 9.0$ & Single-phase \\
\hline 6 & - & 51.5 & - & 3.8 & - & Ga 12.6, In 3.9, Ni 28.1 & Multiple-phase \\
\hline 9 & 30.0 & 36.4 & 24.2 & 6.0 & 3.3 & - & Single-phase \\
\hline 10 & 54.9 & - & 18.3 & 22.8 & 3.0 & B $0.9 \mathrm{Ru} 0.001$ & Multiple-phase \\
\hline
\end{tabular}

poorer in Pd than the bulk. Cleaning the alloy decreased the surface $\mathrm{Ag}$ and $\mathrm{Cu}$ by about $2 \%$ each and increased the Pd by 5 at.\% (not statistically significant). In both the polished and polished-cleaned conditions, bulk compositions were present at the $12.5-\mathrm{nm}$ depth.

Fig. 3 shows surface analyses for alloy 9 in the polished and polished-cleaned conditions. Here, the surface of the polished sample was relatively rich in $\mathrm{Ag}, \mathrm{Cu}$, and $\mathrm{Zn}$ and poor in $\mathrm{Au}$ and $\mathrm{Pd}$ [Fig. 3(a)]. After the sample was cleaned, the abundance of $\mathrm{Ag}$ increased and $\mathrm{Cu}$ decreased by about 5 at.\% at the surface [Fig. 3(b)]. Again, bulk compositions were present at a depth of $12.5 \mathrm{~nm}$. The abundance of Au increased from 0 at.\% at the surface to over 40 at.\% at the 12.5-nm depth.

Depth profile Auger analyses of elements in the alloys exposed to cell-culture medium showed the presence of organic films with thicknesses between 25 and $50 \mathrm{~nm}$. The thickest films $(50 \mathrm{~nm})$ were present on alloy 4; all films consisted primarily of $\mathrm{C}, \mathrm{N}$, and $\mathrm{O}$, with smaller amounts of $\mathrm{S}$ and $\mathrm{Na}$. Because of the organic deposition, it was not possible for the original alloy surface to be located; thus, comparisons of the medium-treated samples with those which were not exposed to medium were difficult.

\section{Discussion.}

Similar kinetic patterns of element release were observed for $\mathrm{Ag}$ and $\mathrm{Cu}$ in alloys with different microstructures and com-

TABLE 2

WAVELENGTHS AND DETECTION LIMITS FOR ATOMIC ABSORPTION

\begin{tabular}{lcc}
\hline \hline Element & $\begin{array}{c}\text { Detection Limit } \\
(\mathrm{ppm})\end{array}$ & $\begin{array}{c}\text { Wavelength } \\
(\mathrm{nm})\end{array}$ \\
\hline $\mathrm{Ag}$ & 0.010 & 328.1 \\
$\mathrm{Au}$ & 0.045 & 242.8 \\
$\mathrm{Cd}$ & 0.013 & 228.8 \\
$\mathrm{Cu}$ & 0.020 & 324.8 \\
$\mathrm{Ga}$ & 0.080 & 287.4 \\
$\mathrm{In}$ & 0.087 & 303.9 \\
$\mathrm{Ni}$ & 0.055 & 341.5 \\
$\mathrm{Pd}$ & 0.035 & 244.8 \\
$\mathrm{Zn}$ & 0.012 & 213.9 \\
\hline
\end{tabular}

positions (Tables 1 and 3 ). For example, Cu exhibited a type I kinetic pattern in single-phase high-gold and low-gold alloys (alloys 1 and 4, respectively), and in a multiple-phase no-gold alloy (alloy 10). These similarities indicate that the chemistry of an element may play a greater role in determining the type of kinetic release pattern than the composition or microstructure of the alloy. However, composition and microstructure must have had some influence upon the kinetics of release, since the 12-hour percentage concentration for $\mathrm{Cu}$ in alloy 10 was significantly lower than in alloys 1 and 4 , and $\mathrm{Cu}$ in alloy 9 was released in a type II pattern (Table 3). Additional testing of more alloys is needed for the roles of composition and microstructure in the release of elements from alloys to be defined.

Equations for the curves used to fit the data points were arbitrarily selected based on least-squares criteria rather than on specific kinetic rate equations. Therefore, each curve is useful as an overall description of the time course of the release of an element, but cannot be used as evidence for a specific mechanism of release. For example, although the logarithmic curve in Fig. 1(a) adequately describes the time course of the release of $\mathrm{Cu}$ from alloy 1 , other mechanistic interpretations of the data are possible. The release might have occurred in two stages by different mechanisms-the first consisting of a rapid increase in $\mathrm{Cu}$ in the first several hours, and the second consisting of a more gradual linear increase of $\mathrm{Cu}$ during the remaining time.

Logarithmic patterns of dissolution similar to those reported in the current study have been observed by investigators using other types of alloys. Marek (1990) reported that mercury was released from dental amalgam into synthetic saliva in a logarithmic pattern which was similar to the type II pattern observed in the present study. Brune (1988) observed logarithmic release of chromium, iron, and molybdenum from ferritic stainless steel into modified Fusayama solution. Muller et al. (1990) reported that nickel was released from $\mathrm{Ni}-\mathrm{Cr}$ Mo alloys into an artificial saliva-type of medium with a pattern which was similar to the type II curves observed in the current study. In a more extensive study, Geis-Gerstorfer et al. (1991) observed types I, II, and III release patterns as well as linear patterns when Ni-Cr-Mo and Co-Cr-Mo alloys were exposed to a lactic acid solution for up to 35 days. The type III pattern was observed only for $\mathrm{Cr}$ in a $\mathrm{Co}-\mathrm{Cr}-\mathrm{Mo}$ alloy. The decrease in the rate of release with time in the types I and II patterns has been attributed to passivation from progressive enrichment of the less labile elements (Goehlich and Marek, 1990; Geis-Gerstorfer et al., 1991). Auger analysis of the medium-treated samples in the current study was unable to confirm this observation because of thick organic film formation on the alloy surface from cell-culture medium. 
TABLE 3

CHARACTERISTICS OF DISSOLUTION vs. TIME CURVES

\begin{tabular}{|c|c|c|c|c|c|}
\hline & & & Relative & & \\
\hline $\begin{array}{l}\text { Alloy/ } \\
\text { Element }{ }^{\dagger}\end{array}$ & Curve Type & $\begin{array}{l}\% \text { Cone } \\
\text { at } 12 \mathrm{~h}^{\ddagger}\end{array}$ & $\begin{array}{c}\text { 48-72-hour Slope } \\
\left(\mathrm{h}^{-1}\right) \text { at } 72 \mathrm{~h}^{\ddagger}\end{array}$ & Curve Shape & $\mathrm{r}^{2}$ \\
\hline \multicolumn{6}{|l|}{ Alloy 1} \\
\hline $\mathrm{Cu}$ & I & 75 & 0.002 & $\log$ & 0.85 \\
\hline \multicolumn{6}{|l|}{ Alloy 4} \\
\hline $\mathrm{Ag}$ & II & 30 & 0.010 & $\log$ & 0.97 \\
\hline $\mathrm{Cu}$ & I & 74 & 0.002 & $\log$ & 0.80 \\
\hline \multicolumn{6}{|l|}{ Alloy 5} \\
\hline $\mathrm{Cd}$ & I & 69 & 0.003 & $\log$ & 0.68 \\
\hline $\mathrm{Cu}$ & $\mathrm{I}$ & 71 & 0.003 & $\log$ & 0.63 \\
\hline \multicolumn{6}{|l|}{ Alloy 6} \\
\hline $\mathrm{Ga}$ & III & 7 & 0.018 & Poly-2 & 0.98 \\
\hline $\mathrm{Ni}$ & III & 7 & 0.019 & Poly-2 & 0.99 \\
\hline \multicolumn{6}{|l|}{$\overline{\text { Alloy } 9}$} \\
\hline $\mathrm{Ag}$ & II & 33 & 0.010 & $\log$ & 0.99 \\
\hline $\mathrm{Cu}$ & II & 32 & 0.010 & $\log$ & 0.99 \\
\hline \multicolumn{6}{|l|}{$\overline{\text { Alloy } 10}$} \\
\hline $\mathrm{Ag}$ & II & 26 & 0.011 & $\log$ & 0.98 \\
\hline $\mathrm{Cu}$ & I & 55 & 0.003 & $\log$ & 0.95 \\
\hline
\end{tabular}

${ }^{\dagger}$ Elements not shown for each alloy did not dissolve enough to allow for analysis.

${ }^{\ddagger}$ Errors approximately $15 \%$ at $p=0.05$, determined graphically.

${ }^{\S} \log =$ Logarithmic; Poly-2 = 2nd-order polynomial.

The types of kinetic patterns of release of elements from dental casting alloys have important consequences for in vitro tests used to assess their cytotoxicity. The time at which an element begins to be released, the rate at which it is released, and the change in the rate of release-all may affect the in vitro cytotoxic behavior of the alloy releasing that element. For example, if the in vitro cytotoxicity of alloy 6 were tested for $12 \mathrm{~h}$, then the alloy might not be called cytotoxic, because the release of its elements at that time would be low. However, if this alloy were tested for $72 \mathrm{~h}$, then the alloy could exhibit significantly greater cytotoxicity [Fig 1(c) and Table 3].

Auger surface-analysis revealed that elements which were released from the alloys in either the polished or polishedcleaned conditions were more abundant at the surface than in the bulk. For example, alloy 1 had a high surface concentration of $\mathrm{Cu}$ (Fig. 2) and released significant amounts of $\mathrm{Cu}$ after 2 and $72 \mathrm{~h}$ (Table 4). The lability of $\mathrm{Cu}$ in this alloy may have been caused by its high surface concentration or the relative absence of Au at the surface (Fig. 2), but it is likely that both factors contributed to the release of $\mathrm{Cu}$. Similar results were observed for $\mathrm{Ag}$ and $\mathrm{Cu}$ in alloy 9 (Fig. 3 and Table 4) and alloy 4 (Table 4).

Smith et al. (1991) reported that preparative proceduressuch as sonication, steam sterilization, irradiation, plasma treatment, and acid treatment-each uniquely altered the surface compositions of metallic and ceramic implant materials. In the present study, cleaning procedures altered dental casting-alloy surface compositions, and these changes probably affected the dissolution behavior of the alloys. Auger analysis of alloys 1 , 4 , and 9 before and after cleaning confirmed that cleaning altered the surface composition. In alloy 1 , the cleaning process increased the proportion of $\mathrm{Au}$ at the surface [Figs. 2 (a) and (b)], which may have been responsible for the decrease in $\mathrm{Cu}$ release at $72 \mathrm{~h}$ (Table 4). In alloy 9 , cleaning increased the proportion of $\mathrm{Ag}$ and decreased the proportion of $\mathrm{Cu}$ to approximately equal levels [Figs. 3 (a) and (b)]. Without $\mathrm{Au}$ at the surface, these proportions of $\mathrm{Ag}$ and $\mathrm{Cu}$ seem to have promoted dissolution.

Although the cleaning process generally reduced the amounts of elements released from the alloys, it did not seem to change the kinetic patterns of dissolution (Tables 3 and 4). For example, the $\mathrm{Cu}$ released from alloy 1 at $2 \mathrm{~h}$ was greater than $40 \%$ of the 72-hour concentration in both the polished and polished-cleaned conditions. Alloy 4 exhibited 2-hour $\mathrm{Cu}$ concentrations which were $56 \%$ and $57 \%$ of the 72 -hour concentrations in the polished and polished-cleaned conditions, respectively. $\mathrm{Ni}$ and $\mathrm{Ga}$, which were released from alloy 6 , were very low at $2 \mathrm{~h}$ in both conditions. If cleaning had changed the kinetic patterns of dissolution significantly, then release of elements at $2 \mathrm{~h}$ should have been affected.

The present study demonstrated that a cleaning treatment altered the quantity of released elements and the percentages of the elements at the surfaces of several dental casting alloys, but did not change the kinetics of the release of the elements. The kinetic patterns of release for each element seemed to depend upon both the element and the alloy composition. These data should be useful in the development of in vitro tests designed for evaluation of the biocompatibility of these types of alloys.

\section{Acknowledgments.}

We thank T.C. Lipson and T.L. Walzak at Surface Science Western, London, Ontario N6A 5B7, for Auger analysis of the 
TABLE 4

CONCENTRATIONS OF ELEMENTS RELEASED INTO CELL-CULTURE MEDIUM BEFORE AND AFTER CLEANING

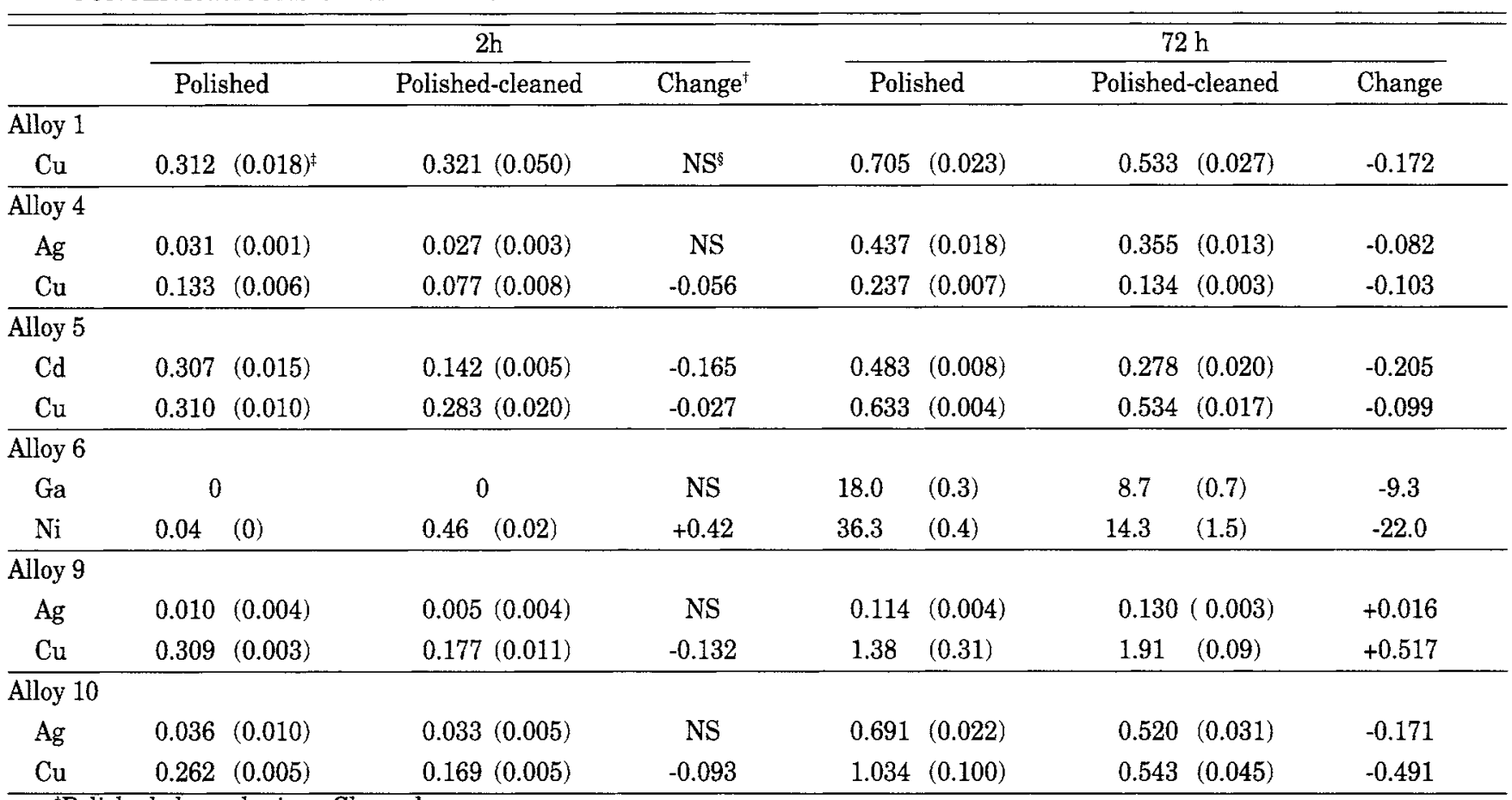

${ }^{\dagger}$ Polished-cleaned minus Cleaned.

*Values in the form Mean (1 SEM), n 3.

${ }^{\circledR} \mathrm{NS}=$ No significant difference $(\mathrm{p}=0.05)$.

alloys, and express appreciation to Dr. Richard Corpron, Susan Strawn, Jackie Dahlgren, and Pat Landry for their cooperation in these investigations.

\section{REFERENCES}

Baier RE, Meyer AE, Natiella JR, Natiella RR, Carter JM (1984). Surface properties determine bioadhesive outcomes: methods and results. I Biomed Mater Res 18:337-355.

Bergman M, Ginstrup $\mathrm{O}$ (1975). Dissolution rate of cadmium from dental gold solder alloys. Acta Odontol Scand 33:199-210.

Brune D (1988). Mechanisms and kinetics of metal release from dental alloys. Int Endod $J$ 21:135-142.

Covington IS, McBride MA, Slagle WF, Disney AL (1985). Quantitization of nickel and beryllium leakage from base metal casting alloys. $J$ Prosthet Dent 54:127-135.

Geis-Gerstorfer J, Sauer KH, Pässler K (1991). Ion release from Ni$\mathrm{Cr}-\mathrm{Mo}$ and $\mathrm{Co}-\mathrm{Cr}-\mathrm{Mo}$ casting alloys. Int $J$ Prosthodont 4:152-158.

Goehlich V, Marek M (1990). Corrosion behavior of Pd-Cu and Pd-Co alloys in synthetic saliva. Dent Mater 6:103-110.
Greppi L, Smith DC, Woodside DG, Varrela T (1991). Nickel hypersensitivity reactions in orthodontic patients (abstract). J Dent Res $70: 361$.

Hao SQ, Lemons JE (1989). Histology of dog dental tissues with $\mathrm{Cu}$ based crowns (abstract). J Dent Res 68:322.

Lappalainen R, Yli-Urpo A (1987). Release of elements from some gold alloys and amalgams in corrosion. Scand J Dent Res 95:364-368.

Marek. M (1990). The release of mercury from dental amalgam: the mechanism and in vitro testing. $J$ Dent Res 69:1167-1174.

Muller AWJ, Maessen FJMJ, Davidson CL (1990). Determination of the corrosion rates of six dental Ni-Cr-Mo alloys in an artificial saliva by chemical analysis of the medium using ICP-AES. Dent Mater 6:63-68.

Smith DC, Pilliar RM, Metson JB, McIntyre NS (1991). Dental implant materials. II. Preparative procedures and surface spectroscopic studies. $J$ Biomed Mater Res 25:1069-1084.

Wataha JC, Craig RG, Hanks CT (1991). The release of elements of dental casting alloys into cell-culture medium. J Dent Res 70:1014-1018.

Wright DC, Gallant RF, Spangberg L (1982). Correlation of corrosion behavior and cytotoxicity in $\mathrm{Au}-\mathrm{Cu}-\mathrm{Ag}$ ternary alloys. J Biomed Mater Res 16:509-517. 